\title{
Not just another diplopia: neurocysticercosis in a postpartum woman
}

\author{
Srikanta Kumar Padhy, Swati Phuljhele, Anubha Rathi, Sohini Mandal
}

Department of Ophthalmology, Dr. Rajendra Prasad Centre for Ophthalmic Sciences, All India Institute of Medical Sciences, New Delhi, India

\section{Correspondence to}

Dr Swati Phuljhele, drmsswati@rediffmail.com

Accepted 11 October 2018

\section{DESCRIPTION}

A 23-year-old woman with a history of child birth 2 weeks back presented to the outpatient department with binocular diplopia and slight blurring of vision in both eyes (BE) for last 1 week. She also had four bouts of vomiting with associated nausea and hemicranial dull headache for last 3 days. The antenatal and immediate perinatal period was uneventful. Previous history as well as systemic history was not significant. The patient was afebrile. On systemic examination, neck stiffness could be elucidated. The blood pressure was recorded to be $124 / 74 \mathrm{~mm} \mathrm{Hg}$. Ocular examination revealed the visual acuity to be $20 / 40$ in BE. There was restricted abduction of the right eye (figure 1) and diplopia charting revealed isolated sixth cranial nerve palsy. Pupillary reaction was brisk in BE with no evidence of relative afferent pupillary defect. Slit lamp evaluation of the anterior segment showed no abnormality. On fundus evaluation, bilateral disc oedema with ill-defined disc margins was noted (figure 2A,B).

Keeping in mind the acute onset of the condition and its occurrence in a postpartum woman, we considered the differential diagnoses of posterior reversible encephalopathy syndrome, pre-eclampsia-induced sixth cranial nerve palsy, idiopathic intracranial hypertension, pituitary tumour and pituitary apoplexy. MRI brain and orbit with MR venography was advised. An urgent referral was made to the neurologist for evaluation and consideration for lumbar puncture and cerebrospinal fluid analysis after controlling intracranial tension (ICT). MRI brain and orbit revealed multiple foci of cystic lesions throughout the brain parenchyma (figure 3) suggestive of neurocysticercosis (NCC) with signs of increased ICT and optic nerve kinking. No intraocular or extraocular cysts were detected. Under

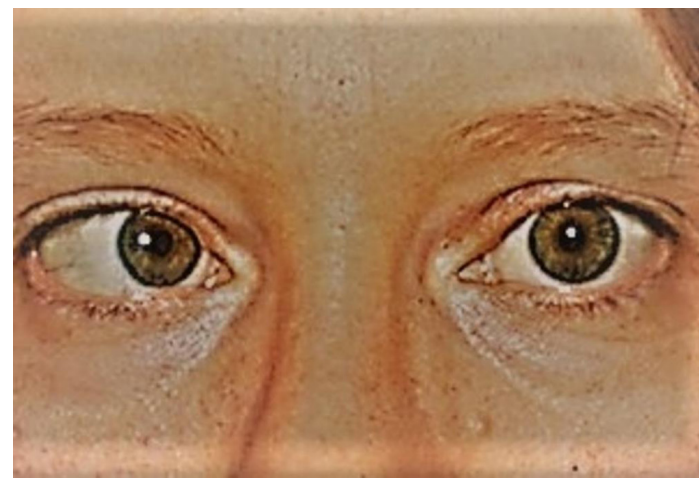

Figure 1 Image showing right eye esodeviation and abduction deficit.

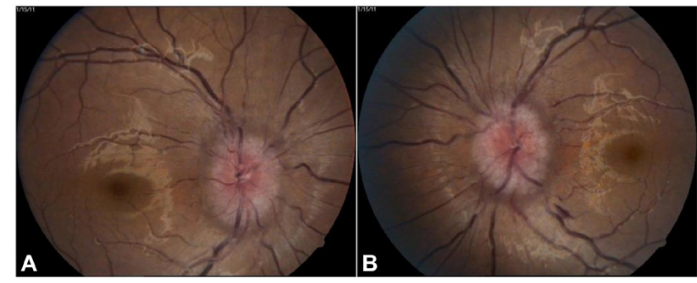

Figure $2(A, B)$ Fundus image of right and left eye showing disc oedema with ill-defined disc margins.

neurologist's guidance, an urgent management with intravenous mannitol, oral acetazolamide was instituted to decrease the raised ICT. Oral steroids and prophylactic oral antiepileptics were also started.

NCC presenting as only diplopia in early postpartum period is a rare phenomenon. The sixth cranial nerve originates from the pons, runs a long course through the cavernous sinus and finally enters the orbit through the superior orbital fossa where it pierces the lateral rectus supplying it. Its only action is abduction of the eyeball. ${ }^{1}$ Raised ICT causes downward displacement with stretching and compression of sixth cranial nerve against the petrous ligament causing non-traumatic paralysis. Seizures are the most common presentation of NCC. The location of the cysts in the brain, stage of infection and host response determine the presentation of the disease which may vary from seizures, hydrocephalus to stroke. ${ }^{2} \mathrm{~A}$ new-onset seizure in a patient with NCC can often be confused with pre-eclampsia and eclampsia particularly during pregnancy and postpartum period. ${ }^{3}$ The effect of pregnancy on the clinical course of NCC is unknown. The management of NCC during pregnancy is mainly symptom based and depends on the presentation. Once a diagnosis of isolated sixth cranial nerve is made, no specific treatment is needed other than decreasing the raised ICT and management of the associated symptoms. ${ }^{4}$

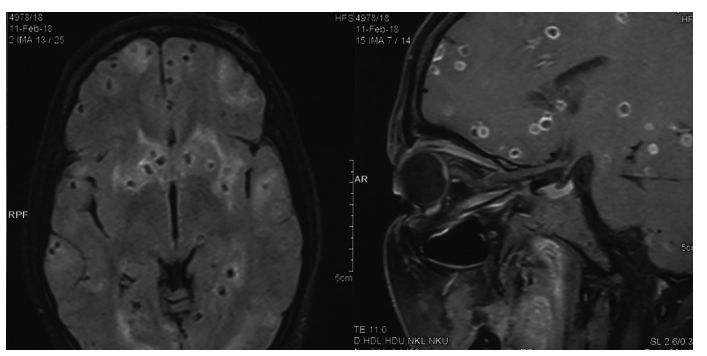

Figure 3 MRI of the brain revealing multiple cystic lesions with perilesional oedema with signs of raised intracranial tension. 


\section{Learning points}

Diagnosis and management of neurocysticercosis (NCC) during pregnancy and postpartum period are challenging.

- History of exposure in endemic area, personal, family and social history are very crucial in suspecting the diagnosis in patients with neurological symptoms.

- Cysticercosis can be transmitted horizontally from the mother to the newborn. Hence, in mothers with NCC, screening for tapeworm infection is exigent.

- Postpartum diplopia should be investigated thoroughly.

- Early management is mandatory in case of postpartum women to prevent untoward outcomes.

Contributors SKP, SP, AR, SM: conception, design, research, analysis and collection of data.
Funding The authors have not declared a specific grant for this research from any funding agency in the public, commercial or not-for-profit sectors.

Competing interests None declared.

Patient consent Obtained.

Provenance and peer review Not commissioned; externally peer reviewed.

\section{REFERENCES}

1 Yevale A, Vasudeva A, Mundkur A, et al. ISolated sixth cranial nerve palsy in a case of severe pre-eclampsia presenting as postpartum diplopia. J Clin Diagn Res 2017:11:QD01-2.

2 Webb C, Rosa M, Olson G, et al. Neurocysticercosis in pregnancy. AJP Rep 2018:8:e51-6.

3 Webb CM, White AC. Update on the diagnosis and management of neurocysticercosis. Curr Infect Dis Rep 2016;18:44.

4 Nash TE, Mahanty S, Loeb JA, et al. Neurocysticercosis: A natural human model of epileptogenesis. Epilepsia 2015;56:177-83.

Copyright 2018 BMJ Publishing Group. All rights reserved. For permission to reuse any of this content visit http://group.bmj.com/group/rights-licensing/permissions.

BMJ Case Report Fellows may re-use this article for personal use and teaching without any further permission.

Become a Fellow of BMJ Case Reports today and you can:

- Submit as many cases as you like

- Enjoy fast sympathetic peer review and rapid publication of accepted articles

- Access all the published articles

Re-use any of the published material for personal use and teaching without further permission

For information on Institutional Fellowships contact consortiasales@bmjgroup.com

Visit casereports.bmj.com for more articles like this and to become a Fellow 